

\section{Sumário}

EDITORIAL

Ingo Wolfgang Sarlet, Lilian Rose Lemos Rocha e Patrícia Perrone Campos Mello

1. Direitos Fundamentais, hermenêutica e meio ambiente

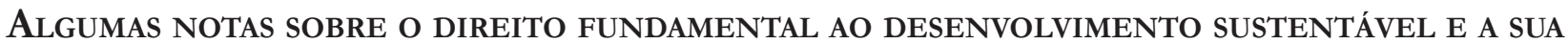
DIMENSÃO SUBJETIVA E OBJETIVA.

Ingo Wolfgang Sarlet e Gabriel de Jesus Tedesco Wedy

El DERECHO HUMANO AL AGUA Y AL SANEAMIENTO.

Belén Burgos Garrido

Até onde VAi o DiReito CONSTITUCIONAL Ao MEIO AMBIENTE ECOlOGICAMENTE EQUILIBRADO? UMA ANÁLISE SOBRE O POSICIONAMENTO BRASILEIRO FRENTE AO NOVO CONSTITUCIONALISMO

LATINO-AMERICANO

Mariana Bruck de Moraes Ponna Schiavetti e Maria Eugênia Bruck de Moraes

El DERECHO HUMANO AL ACCESO A LA INFORMACIÓN AMBIENTAL Y LA JURISPRUDENCIA INTERAMERICANA.

Gonzalo Aguilar Cavallo Garrido

As MÚlTIPLAS DIMENSÕES DO DIREITO FUNDAMENTAL À CIDADE.

Zenildo Bodnar e Priscilla Linhares Albino

Na dúvida EM Favor da natureza? LeVar a sério a Constituição Ecológica na Época do Antropoceno.

Patryck de Araújo Ayala e Mariana Carvalho Victor Coelho

2. Direitos dA NATUREZA................................................................................. 164

A sala de EMERgênCia Ambiental: A PRoteÇão dos direitos da natureza na AmÉrica

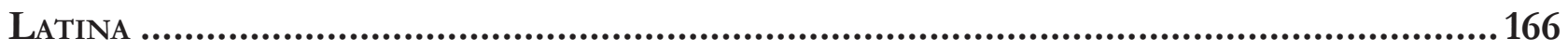

Lilian Rose Lemos Rocha

Procedural theory of THE SubJect of LAW AND NON-HUMan ANimals: CRiteria for RECOGNITION OF LEGAL SUBJECTIVITY FROM THE PERSPECTIVE OF CRITICAL THEORY

Sthéfano Bruno Santos Divino 
Os “ANIMAIS DE PRODUÇÃO” PARA ALIMENTAÇÃO HUMANA E O DIREITO CONSTITUCIONAL AMBIENTAL E ECOLÓGICO: PARADOXOS ÉTICO-JURÍDICOS

Juliane Caravieri Martins e Cicília Araújo Nunes

3. Povos indígenas

Povos Indígenas E PRoteção da NATUREZA: A CAMINHO DE UM “GIRO HERMENÊUTICo ECOCÊNTRICO"

Patrícia Perrone Campos Mello e Juan Jorge Faundes Peñafiel

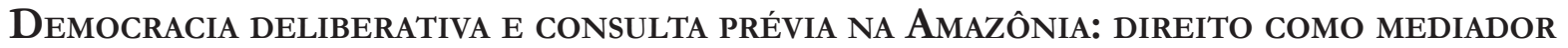

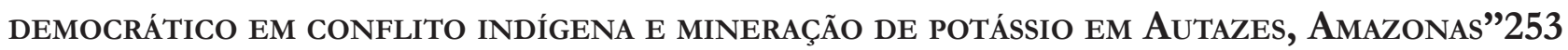
Acursio Ypiranga Benevides Júnior

Rafael da Silva Menezes

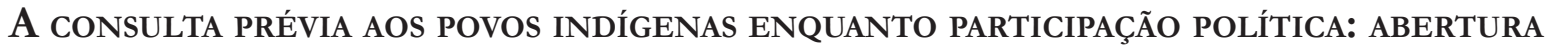
CONSTITUCIONAL BRASILEIRA A ROTAS ALTERNATIVAS DE PROTEÇÃO AMBIENTAL.

Laura Fernanda Melo Nascimento e Adriano Fernandes Ferreira

4. ECOFEMINISMO

MEIO AMbIENTE, CUIDADo E DIREITO: INTERSECÇÕES TEÓRICAS E PRÁTICAS DESDE A DIALÉTICA DA DIFERENÇA 294

Gustavo Seferian e Carol Matias Brasileiro

ECOFEMINISMO INTERSECCIONAL E DECOLONIAL NO DIREITO BRASILEIRO: A NOVA POLÍTICA estadual de SEgurança de barRagens de Minas Gerais.

Émilien Vilas Boas Reis e Vanessa Lemgruber

\section{INSTRUMENTOS E INCENTIVOS PARA A CONCRETIZAÇÃO DA PROTEÇÃO AO MEIO} AMBIENTE

STARTUP E O DESAFIO DO COMPLIANCE

Grace Ladeira Garbaccio, Alexandra Aragão, Vanessa Morato Resende e Ana Walêska Xavier Araújo

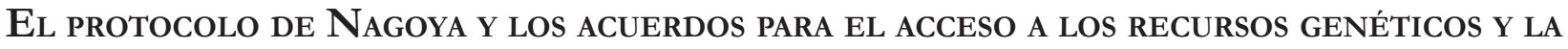
PARTICIPACIÓN JUSTA Y EQUITATIVA EN LOS BENEFICIOS QUE SE DERIVEN DE SU UTILIZACIÓN: UNA PROPUESTA DISCUTIDA

Roberto Concha Machuca

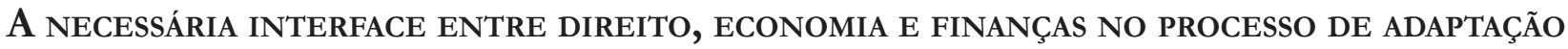
Às MUDANÇAS CLIMÁTICAS 363

Fernanda Dalla Libera Damacena 
RELEVÂNCIA E ESTRATÉGIAS PARA VIABILIZAÇÃo DA CRIAÇÃO DE CORREDORES ECOLÓGICOS EM Área da Mata Atrântica setentrional

Juliana Garcia Vidal Rodrigues, Sueli Aparecida Moreira e Eliza Maria Xavier Freire

AgrotóXICOS, DOMINAÇÃO E FRONTEIRAS: SIGNIFICAÇÃO, RELAÇÃO E PERSPECTIVAS SOBRE O PACOTE TECNOLÓGICO AGRÍCOLA E A AMAZÔNIA BRASILEIRA 418

Giovanni Martins de Araújo Mascarenhas, José Antônio Tietzmann e Silva e Luciane Martins de Araújo

SERÁ O SANEAMENTO BÁSICO UMA ESPÉCIE DE SERVIÇO PÚBLICO DE INTERESSE LOCAL? UM ESTUDO À LUZ DA TEORIA DAS CAPACIDADES ESTATAIS APLICADA AOS MUNICÍPIOS BRASILEIROS.. 440 Thaís de Bessa Gontijo de Oliveira e Fabiana de Menezes Soares

IMPASSES DA ADOÇÃO DA TÉCNICA DE DESSALINIZAÇÃO: BENEFÍCIOS PARA A SAÚDE PÚBLICA E DANOS PARA O MEIO AMBIENTE.

Ivone Rosana Fedel, André Studart Leitão e Gerardo Clésio Maia Arruda

As CONTRATAÇõES PÚBliCAS SUSTENTÁVEIS E A IMPLEMENTAÇão DA META 12.7 DOS OBJETIVOS PARA O DESENVOLVIMENTO SUSTENTÁVEL (ODS) NO BRASIL: AVANÇOS E RETROCESSOS .492 Lucas Campos Jereissati e Álisson José Maia Melo

6. Acesso À justiça em matéria AMbiental.

Desafíos del acceso a la justicia Ambiental en Chile. Jairo Enrique Lucero Pantoja, Gonzalo Aguilar Cavallo e Cristian Contreras Rojas

CONSIDERAÇÕES SOBRE A PARTICIPAÇÃO JUDICIAL DIRETA EM DEFESA DO MEIO AMBIENTE NO Brasil, No Equador e na Bolívia . .556 Leonardo Leite Nascimento e Valmir César Pozzetti

JURISDIÇÃo CONSTITUCIONAL E PATRIMÔNIO CULTURAL: UM ESTUdO DE CASO DA ADPF 206.575 Almir Megali Neto, Flávio Couto Bernardes e Pedro Augusto Costa Gontijo

A TESE DE IMPRESCRITIBILIDADE DE DANOS AMBIENTAIS EM REPERCUSSÃO GERAL DO SUPREMO TRIBUNAL FEDERAL E A POSSIBILIDADE DE APLICAÇÃO DA TEORIA DO RISCO AGRAVADO............602 Vicente de Paulo Augusto de Oliveira Júnior e Daniel Pagliuca

7. Mudanças Climáticas.

Agenda 2030: EMERgênCIA CLIMÁtiCa E O PAPEL DAS INSTITUIÇões PÚBLICAS .624 Luiz Edson Fachin

DÉfis ET PERSPECTIVES POLITIQUES, INSTITUTIONNELles ET NORMATIVES DES AsSEMbléES CITOYENNES: UNE APPROCHE DEPUIS L'EXEMPLE DE LA CONVENTION CITOYENNE SUR LE CLIMAT .636

Benoit Delooz 
Cambio Climático e Inversiones: Esbozando estrategias de armonización para

Andrea Lucas Garí, Jaime Tijmes-Ihl e Johanna Sagner-Tapia

MudANÇAS CLIMÁTICAS E RESPONSABILIDADE CIVIL: UM ESTUDO DE CASO SOBRE A REPARAÇÃo DE

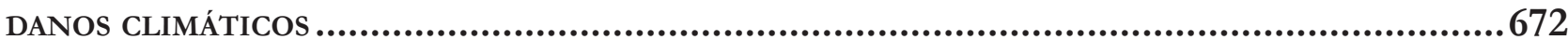

Sabrina Jiukoski da Silva e Thatiane Cristina Fontão Pires 


\title{
As múltiplas dimensões do direito fundamental à cidade*
}

\section{The multiple dimensions of the fundamental right to the city}

\author{
Zenildo Bodnar** \\ Priscilla Linhares Albino***
}

\section{Resumo}

Este artigo tem como propósito o estudo do direito à cidade como direito fundamental em suas múltiplas dimensões. O seu objetivo é analisar o direito à cidade enquanto direito fundamental, sua relação com a dignidade humana, bem como relacionar a sua caracterização com as diversas dimensões de direitos fundamentais. Inicia com uma breve incursão acerca dos aspectos sociais, econômicos e ambientais, seguindo com apontamentos acerca do relevo conferido à dignidade da pessoa humana, a fim de caracterizar uma cidade sustentável. Prossegue abordando a Teoria dos Direitos Fundamentais e o seu entrelaçamento ao direito à cidade, sob o vértice constitucional. Encerra com apontamentos que visam à demonstração da conexão inarredável do direito à cidade com as cinco dimensões dos direitos. Quanto à metodologia, utiliza a base lógica indutiva por meio de pesquisa bibliográfica. Como resultado, caracteriza o direito à cidade como direito fundamental, considerando a sua intensa e direta relação com a dignidade humana e com o meio ambiente; identifica relações do direito à cidade com as diversas dimensões dos direitos fundamentais, o que atrai deveres compartilhados para a sua progressiva e efetiva implementação.

Palavras-chave: Dignidade humana. Direito à cidade. Direitos fundamentais. Meio ambiente.

Pós Doutorado em Direito Ambiental pela Universidade de Alicante - Espanha. Professor nos programas de Doutorado e Mestrado em Ciência Jurídica da Universidade do Vale do Itajaí. Foi Juiz Federal e atualmente é Registrador de Imóveis. E-mail: zenildo.bodnar1@gmail.com.

\section{Abstract}

This article aims to study the right to the city as a fundamental right in its multiple dimensions. Its objective is to analyze the right to the city as a fundamental right, its relation to human dignity, as well as to relate its characterization to the different dimensions of fundamental rights. It begins with a brief incursion on social, economic and environmental aspects, followed by notes on the importance given to the dignity of the human person, in order to characterize a sustainable city. It continues approaching the Theory of Fundamental Rights and its intertwining with the right to the city, under the constitutional vertex. It ends with notes that aim to demonstrate the unbelievable connection between the right to the city and the five dimensions of rights. As for the methodology, it uses the inductive logic base through bibliographic research. As a result, it characterizes the right to the city as a fundamental right, considering its intense and direct relationship with hu- 
man dignity and the environment; identifies relations between the right to the city and the different dimensions of fundamental rights, which attracts shared duties for its progressive and effective implementation.

Keywords: Human dignity. Right to the city. Fundamental rights. Environment.

\section{Introdução}

O futuro está nas cidades, nas suas tramas, vivências, desafios e conflitos. A intensidade dos vínculos, bem como a diversidade de perspectivas ambiental, social e econômica requer aportes hermenêuticos adequados, especialmente para que o Direito cumpra, também, a sua função promocional de outorga da máxima efetividade dos direitos fundamentais.

Para além do desenvolvimento, os aglomerados urbanos trouxeram consigo inúmeras oportunidades e, paralelamente, imensos e complexos desafios.

Nesse cenário, a cidade passou a se encontrar visceral e integralmente vinculada aos direitos fundamentais e qualquer tentativa de separação seria inócua, a se considerar a automaticidade de interlocução existente entre as duas categorias.

Os vínculos existentes se espraiam não de maneira isolada, mas da primeira à última dimensão de direitos, gerando, assim, uma pluralidade que contempla, à guisa de exemplo, os contratos de propriedade, a moradia, as políticas públicas prestacionais, o meio ambiente, a democracia participativa, assim como o direito à informação, à sociedade tecnológica, à realidade virtual e a percepção de paz no ambiente das cidades.

Em meio a uma conjuntura de avanços trazidos pela Constituição da República Federativa do Brasil de 1988 (CRFB/88), especialmente no que se refere aos direitos sociais e fundamentais, tem-se o direito à cidade, tema central deste artigo, analisado sob a perspectiva da sua fundamentalidade e, ainda mais, da vinculação estreita com, ao menos, cinco dimensões dos direitos fundamentais.

Considerando-se o cenário mencionado, o objetivo deste artigo é analisar o direito à cidade enquanto direito fundamental, sua relação com a dignidade humana, bem como relacionar a sua caracterização com as diversas dimensões de direitos fundamentais.

O problema de pesquisa identificado consiste no risco de baixa efetividade do direito à cidade, compreendido enquanto manifestação específica e exclusiva de uma das dimensões dos direitos fundamentais. Essa problemática não está relacionada à efetividade do direito, mas aos critérios hermenêuticos quando o conteúdo do direito à cidade dialoga, intensamente, com outros direitos fundamentais diretamente relacionados.

Há justificativa teórica para a pesquisa, considerando-se a ausência de reflexões específicas sobre a temática do direito à cidade relacionada com as múltiplas dimensões dos direitos fundamentais e com a dignidade humana, e, principalmente, a importância social do direito à cidade para o exercício pleno da cidadania e dos direitos fundamentais.

O estudo está dividido em três momentos. No primeiro, aborda-se $a$ cidade sustentável e as suas dimensões social, ambiental e econômica, apontando a dignidade humana como valor imensurável a esse contexto. No segundo momento analisa-se, especificamente, a fundamentalidade do direito à cidade. Por fim, no terceiro, a pesquisa busca conectar o direito à cidade às cinco dimensões dos direitos fundamentais.

Quanto à metodologia, foi utilizada a base lógica indutiva por meio da pesquisa bibliográfica a ser utilizada no desenvolvimento da pesquisa, compreende o método cartesiano quanto à coleta de dados e, no relatório final, o método indutivo com as técnicas do referente, da categoria, dos conceitos operacionais da pesquisa bibliográfica e do fichamento. ${ }^{1}$

PASOLD, Cesar Luiz. Metodologia da pesquisa jurídica: teoria e prática. 13. ed. Florianópolis: Conceito Editorial, 2015. p. 97-99. 


\section{A cidade e suas dimensões ambiental, econômica e social}

Nas últimas quatro décadas, as cidades caminharam em sentido oposto à sua finalidade primordial, que seria a congregação de pessoas, e passaram a dispersá-las.

E isto ocorreu em razão de esses aglomerados urbanos terem sofrido mudanças estruturais na dinâmica de construção social, política, econômica e física, a fim de comportar o novo ritmo civilizacional e abrigar uma população cada vez mais regida pela quarta revolução industrial ${ }^{2}$ (digital) e pela lógica capitalista.

Nessa nova Sociedade Informacional ${ }^{3}$ mundial, delineada no século XXI, é possível identificar 33 megacidades $^{4}$ e, sem qualquer perspectiva de desaceleração desta curva ascendente, estima-se que chegarão a 39 no ano de $2030^{5}$.

Haverá, assim, continuidade na pressão exercida sobre os recursos naturais planetários, exsurgindo desafios paralelos ao processo vertiginoso de urbanização.

Esse aumento populacional, em sua maior parte, segundo Morin ${ }^{6}$, envolverá países em desenvolvimento, cujos espaços urbanos acolherão, ao menos, 2 bilhões de habitantes a mais do que hoje.

A população mundial contemporânea é estimada em 7.815.000.0007, sendo 55\% moradores de áreas urbanas e com expectativa de que essa proporção aumente para $70 \%$ até $2050^{8}$, o que se traduz em 6,3 bilhões de pessoas residindo nas cidades em todo o mundo, consequência da mais intensa fase de urbanização da história humana. ${ }^{9}$

No Brasil a população urbana saltou de 26,3\%, em 1940, para 81,2\%, em 2000, tendo os dados de 2018 projetado um aumento para $86,6 \%$ nesse cenário. ${ }^{10}$

Em números absolutos, em 1940, a população que residia nas cidades era de 18,8 milhões de habitantes, enquanto, no ano 2000, era de, aproximadamente, 138 milhões. Atualmente, com lastro nas últimas estimativas do Instituto Brasileiro de Geografia e Estatística (IBGE), a projeção da população do Brasil, em agosto de 2020, é de 211.874.561 habitantes. ${ }^{11}$

Referidos números geram alguma apreensão em razão de a sociedade se desenvolver com elevada carga de desigualdade econômica, social e ambiental.

Os diversos fatores de assimetria envolvem questões de caráter sociológico, territorial, econômico e cultural, e seu incremento, também, pode ser atribuído às mudanças advindas da globalização ${ }^{12}$.

\footnotetext{
2 É do conhecimento dos autores que não é unívoca a divisão quanto ao período das revoluções industriais, como se observa nas obras La Era del Acesso (2000) e A Terceira Revolução Industrial (2012), ambas de Jeremy Rifkin. Entretanto, opta-se pela divisão feita por Klaus Schwab em sua obra A quarta revolução industrial. SCHWAB, Klaus. A quarta revolução industrial. São Paulo: Edipro, 2016; RIFKIN, Jeremy. La era del acesso. Buenos Aires: Paidós, 2000; RIFKIN, Jeremy. A terceira revolução industrial: como o poder lateral está transformando a energia, a economia e o mundo. São Paulo: M. Books do Brasil, 2012. p. 15-16.

3 CASTELLS, Manuel. Sociedade em rede. 20. ed. São Paulo: Paz e Terra, 2019. p. 84.

4 ORGANIZAÇÃO DAS NAÇÕES UNIDAS HABITAT. Programa das Nações Unidas para os Assentamentos Humanos. World Cities Report 2016. Disponível em: http://wcr.unhabitat.org/ Acesso em: 28 set. 2020.

5 EUROMONITOR INTERNACIONAL. Megacities: Developing Country Domination. 2018. Disponível em: https:// go.euromonitor.com/strategy-briefing-cities-2018- megacities.html Acesso em: 26 set. 2020.

MORIN, Edgar. A via para o futuro da bumanidade. Rio de Janeiro: Bertrand Brasil, 2013. p. 243.

WORLDOMETERS. População mundial. Disponível em: https://www.worldometers.info/br/ Acesso em: 26 set. 2020.

8 ORGANIZAÇÃO DAS NAÇÕES UNIDAS. ONU prevê que cidades abriguem 70\% da população mundial até 2050. 2019. Disponível em: https://news.un.org/pt/story/2019/02/1660701 Acesso em: 27 set. 2020.

9 UNITED NATIONS POPULATION FUND. The power of choice. Disponível em: https://www.unfpa.org/swop-2018 Acesso em: 26 set. 2020.

10 MARICATO, Ermínia. Brasil, cidades: alternativas para a crise urbana. Petrópolis, RJ: Vozes, 2001.

11 INSTITUTO BRASILEIRO DE GEOGRAFIA E ESTATÍSTICA. População do Brasil. Disponível em: https://www.ibge.gov. br/apps/populacao/projecao/ Acesso em: 26 set. 2020.

12 O termo globalização também pode ser compreendido como mundialização. MORIN, Edgar. A via para o futuro da bumanidade.
} 
Os tempos atuais refletem os efeitos da indústria cultural e da mundialização da economia e da cultura, desencadeando, assim, uma série de transformações nas configurações espaciais e nas dinâmicas urbanas que influenciam diretamente no modo de vida da Sociedade e em suas relações coletivas. As cidades estão sobremaneira interconectadas e "os acontecimentos locais são modelados por eventos ocorrendo a muitas milhas de distância e vice-versa". ${ }^{13}$

Morin considera a mundialização "a origem do agravamento do destino de populações vulneráveis", responsável por reforçar a desigualdade por toda a parte, apontando que "um quinto da humanidade consome (e produz) sozinho os quatro quintos da riqueza mundial."14

O enfrentamento direto dos abismos causados pelas desigualdades sociais entre nações, e até mesmo dentro delas, constitui medida inadiável e objeto primordial de pauta governamental em diversos países. Somente com foco nesse ponto poderão ser desenvolvidas ou recriadas cidades mais humanas.

Uma cidade sustentável ${ }^{15}$ verdadeiramente, para além de seus projetos arquitetônicos ecologicamente adequados, não pode prescindir de modificar a situação de grupos que vivem em situação de vulnerabilidade socioambiental ${ }^{16}$, garantindo, também, a eles o meio ambiente como bem de caráter difuso, transindividual e coletivo de uso comum do povo.

Segundo Petermann e Cruz, coloca-se como desafiador o estabelecimento da noção de pertencimento a um mesmo corpo social político em uma "Sociedade com elevado desequilíbrio social, porque não são estabelecidos laços de solidariedade entre os distintos grupos que vivem em locais diferentes, representam papéis distintos e estão imersos em realidades díspares." ${ }^{17}$

Em exame a essa situação, o relatório Cidades do $M u n d 0^{18}$ concluiu que o atual modelo de urbanização global é insustentável, sendo necessário criar novos padrões para responder a desafios como desigualdades sociais e a proliferação de favelas, especialmente nos países em desenvolvimento.

A apontada crise demográfica se amplifica, na análise de Morin ${ }^{19}$, pelo somatório da superpopulação dos países pobres, da diminuição populacional dos países ricos e da intensificação dos fluxos migratórios engendrados pela miséria.

Para além disso, há uma desproporção alarmante entre países ricos e pobres sobre o consumo e a demanda por atividades e serviços por parte do Estado nas áreas urbanas, como água, energia, gás e saneamento.

A pressão sobre esses se torna a cada dia mais intensa, exigindo atuação e estrutura compatíveis e integradas, assim como o uso da ciência, da tecnologia e de recursos financeiros para seguir em direção a um futuro sustentável.

Esse cenário desafiador favoreceu o aumento das moradias precárias nas periferias e favelas, situação que deve piorar especialmente nos países em desenvolvimento, segundo dados do World Cities Report $2016^{20}$.

\footnotetext{
Rio de Janeiro: Bertrand Brasil, 2013.

13 GIDDENS, A. As consequências da modernidade. São Paulo: Ed. Unesp, 1990. p. 69.

14 MORIN, Edgar. A via para o futuro da humanidade. Rio de Janeiro: Bertrand Brasil, 2015. p. 142.

15 Segundo o art. $2^{\circ}$ da Lei n. 10.257/2001, cidade sustentável é “o direito à terra urbana, à moradia, ao saneamento ambiental, à infraestrutura urbana, ao transporte e aos serviços públicos, ao trabalho e ao lazer, para as presentes e futuras gerações.”

16 Sobre o tema vulnerabilidade socioambiental, ver ALVES, Henrique Prates da Fonseca. Vulnerabilidade socioambiental na metrópole paulistana: uma análise sociodemográfica das situações de sobreposição espacial de problemas e riscos sociais e ambientais. Revista Brasileira de Estudos de População, v. 23, p. 43-59, 2006.

17 PETERMAN, Vânia; CRUZ, Paulo Márcio. (Des)Igualdade e sustentabilidade social: do patrimônio ambiental todos são herdeiros. Justiça do Direito, v. 31, n. 1, p. 24-44, jan./abr. 2017. p. 32.

18 ORGANIZAÇÃO DAS NAÇÕES UNIDAS HABITAT. Relatório Cidades do Mundo. 2016. Disponível em: https:// nacoesunidas.org/atual-modelo-de-urbanizacao-e-insustentavel-onu-habitat-relatorio/ Acesso em: 28 set. 2020.

19 MORIN, Edgar. A via para o futuro da bumanidade. Rio de Janeiro: Bertrand Brasil, 2015. p. 26.

20 ORGANIZAÇÃO DAS NAÇÕES UNIDAS HABITAT. Programa das Nações Unidas para os Assentamentos Humanos. World Cities Report 2016. Disponível em: http://wcr.unhabitat.org/ Acesso em: 28 set. 2020.
} 
Além disso, o advento da pandemia ${ }^{21}$, desencadeada pelo vírus Covid-19, assolou o mundo no decorrer dos anos 2019/2020, deixando milhares de pessoas desempregadas ou vivendo na informalidade e evidenciando que a população de baixa renda é a sua grande vítima.

Nessa ordem de ideias, o custo ambiental ${ }^{22}$ será cada vez mais alto, em razão da excessiva pressão exercida sobre o meio ambiente, posto que está diretamente relacionada a fatores sociais e econômicos.

Em artigo que baliza a sustentabilidade como guia de ação para a humanidade, Ferrer pontua que é ela, sem dúvida, o paradigma da pós-modernidade, tratando-se não somente de objetivo, mas também de caminho. Contudo, segundo o autor, faz tempo que o modelo de produção e consumo adotado pela Sociedade atual conduz a um colapso, tratando-se as leis ambientais apenas de uma reação a esta certeza. ${ }^{23}$

Nesse cenário, extrai-se da análise da realidade contemporânea que o planejamento dos complexos urbanos e as respectivas políticas públicas não bastam quando visam, somente, à sustentabilidade ${ }^{24}$ ambiental.

É preciso que almejem a sustentabilidade de longo alcance - e em todas as suas dimensões; aquela que se atenta aos integrantes da comunidade e às questões relevantes que os envolvem.

Para além do empenho contínuo visando a ações de conteúdo material, a exemplo da utilização adequada de recursos naturais, a destinação correta do lixo e a ocupação de zonas por indústrias e comércio, imprescindível o empenho pela concretização do conceito de sustentabilidade social ${ }^{25}{ }^{26}$ e a integração das diferenças, com foco na cidadania global.

Segundos os dados do relatório da Síntese de Indicadores Sociais (SIS-IBGE) ${ }^{27}$, de 2018, o Brasil possui 13,5 milhões de pessoas na pobreza extrema, que vivem com até $\mathrm{R} \$ 145,00$ por mês. ${ }^{28}$ Os dados informam, ainda, que 11,6 milhões de habitantes habitam imóveis com mais de 3 moradores por dormitório, o que é considerado adensamento excessivo.

21 Evento que teve início na China em dezembro 2020.

22 Neste cenário de pandemia, a situação tende a se agravar demasiadamente, mormente em decorrência do descarte diário de milhares de recipientes de álcool, máscaras, luvas e demais equipamentos de segurança utilizado pelos trabalhadores da área da saúde, acrescidos do lixo hospitalar que se agiganta, e muito, no meio ambiente.

23 FERRER, Gabriel Real. El principio de no regresión ambiental a la luz del paradigma de la sostenibilidad. In: CHACON, Mario Peña (org.). El principio de no regresión ambiental en iberoamérica. Gland (Suiza): Universidad de Costa Rica: Unión Internacional para la Conservación de la Naturaleza (UICN). Comisión Mundial de Derecho Ambiental, 2015. Disponível em: https://portals.iucn.org/ library/sites/library/files/documents/EPLP-084.pdf Acesso em: 26 set. 2020.

24 Tem-se conhecimento de que as dimensões reputadas ao termo Sustentabilidade não são unívocas e que para alguns doutrinadores, como Juarez Freitas, em sua obra Sustentabilidade: direito ao futuro, as dimensões ética e jurídico-político também são compreendidas pela Sustentabilidade. FREITAS, Juarez. Sustentabilidade: direito ao futuro. 2. ed. Belo Horizonte: Fórum, 2012. p. 59. Contudo, para o presente estudo serão adotados somente os três vértices tradicionais — ambiental, social e econômico — nos moldes feitos por grande parte da doutrina nacional, como NALINI, José Renato; SILVA NETO, Wilson Levy Braga da. Cidades inteligentes e sustentáveis: desafios conceituais e regulatórios. Revista de Direito da Administração Pública, v. 1, n. 1, 2017. p. 6-7. Disponível em: http://www.redap.com.br/index.php/redap/article/view/107 Acesso em: 28 set. 2020.

25 A dimensão social da Sustentabilidade, segundo Garcia, é tida como capital humano e reveste-se do aspecto social relacionado às qualidades dos seres humanos, baseando-se em um processo de aumento da qualidade de vida da população, calcado na redução das discrepâncias entre a riqueza e a miséria, com paridade do padrão de renda e acesso, dentre outros direitos, à educação, à moradia e à alimentação. GARCIA, Denise Schmitt Siqueira. Sustentabilidade e Ética: um debate urgente e necessário. Revista Direito Culturais - URI, Santo Ângelo, v. 15, p. 51-75, 2019. p. 51-75.

26 UNESCO. Educação para a cidadania global (ECG): a abordagem da UNESCO. 2015. Disponível em: http://www.unesco.org/ new/fileadmin/MULTIMEDIA/FIELD/Brasilia/pdf/brz_ed_global_citizenchip_brochure_pt_2015.pdf Acesso em: 26 set. 2020.

27 INSTITUTO BRASILEIRO DE GEOGRAFIA E ESTATÍSTICA. Síntese de Indicadores Sociais (SIS). 2018. Disponível em: https://www.ibge.gov.br/estatisticas/sociais/habitacao/9221-sintese-de-indicadores-sociais.html? =\&t=o-que-e Acesso em: 28 set. 2020 .

28 Paralelamente, baseando-se em um estudo da Organização Não-Governamental Oxfam, tem-se que entre 18 de março e 12 de julho de 2020, o patrimônio dos 42 bilionários existentes no Brasil passou de US\$123,1 bilhões (cerca de R\$ 629 bilhões) para US\$ 157,1 bilhões (cerca de R \$ 839,4 bilhões). PATRIMÔNIO dos super-ricos brasileiros cresce US\$ 34 bilhões durante a pandemia, diz Oxfam. G1 Globo, 2020. Disponível em: https://g1.globo.com/economia/noticia/2020/07/27/patrimonio-dos-super-ricosbrasileiros-cresce-us-34-bilhoes-durante-a-pandemia-diz-oxfam.ghtml Acesso em: 27 set. 2020. 
Somado a isso, 31,1 milhões de brasileiros (16\% da população) não possuem acesso à água fornecida por meio de rede geral de abastecimento; 74,2 milhões (37\% da população) vivem em áreas sem coleta de esgoto e outros 5,8 milhões não têm banheiro em casa. ${ }^{29}$

A melhora da qualidade geral de vida das populações se torna um fator essencial para o êxito de projetos futuros construídos por meio de políticas públicas urbanas.

O direito à cidade transcende a liberdade individual de ter acesso aos recursos urbanos. Para Harvey ${ }^{30}$, afigura-se num direito de mudar a nós mesmos e, assim, a cidade, conformando-se num "direito coletivo e não individual, já que essa transformação depende do exercício de um poder coletivo para remodelar os processos de urbanização."

Esse quadro é objeto da tese central da obra La ciudad de los ricos y la cindad de los pobres, de Secchi ${ }^{31}$, para quem as desigualdades sociais são um dos aspectos mais significativos que ensejam reflexão acerca do projeto urbano de uma cidade, salientando a imensa responsabilidade do urbanismo para piorar ou melhorar a assimetria social.

Atribuindo a injustiça espacial urbana à injustiça social, o autor afirma que, aliada ao dilema da mobilidade nas cidades e às implicações das mudanças climáticas, estas atingem direitos fundamentais dos cidadãos. ${ }^{32}$

A própria ideia profusamente divulgada de desenvolvimento, como fórmula-padrão que desconsidera os contextos humanos e culturais, é "cega" diante das devastações e degradações que produz, consoante reflete Morin $^{33}$.

Resta evidenciado, portanto, que não é mais possível estabelecer o debate ecológico sem enfrentar o inescapável prisma social.

Fundamental, outrossim, introduzir, no debate ambiental urbano, a perspectiva da redistribuição de renda, buscando o equilíbrio do indivíduo com o uso dos recursos naturais e também com os demais seres humanos, a fim de evitar um modelo de preservação ambiental que privilegie apenas a minoria. ${ }^{34}$

Em relação aos aglomerados urbanos, que deveriam ser compreendidos como local que abraça a necessidade do outro, abarcando manifestações de diversidade e relações humanas, têm-se colocado estes como entes segregadores e reveladores de uma sociedade estruturalmente desigual.

A discrepância entre as realidades vivenciadas dentro de uma mesma cidade, por indivíduos que pertencem a um mesmo corpo social e comunidade política, salta aos olhos e produzem danos concentrados que afetam sobremaneira as camadas mais pobres da população.

Assim, vê-se o direito à cidade entrelaçado irrefutavelmente ao direito à integridade do meio ambiente em razão da sua incidência direta na existência humana e, via de regra, em sua dignidade.

A degradação dos ecossistemas ao longo dos anos gerou impactos não somente ambientais, mas sociais e econômicos imensuráveis, acarretando mudanças climáticas, poluição, diminuição da biodiversidade, perda de produtividade na agricultura, aumento de doenças, da exclusão social e da pobreza, dentre tantos outros desafios que passaram a repercutir no âmago jurídico.

Por ser assim, incontornável a exigência de ser o direito à cidade guindado ao núcleo dos direitos funda-

\footnotetext{
29 INSTITUTO TRATA BRASIL. Painel Saneamento Brasil. 2018. Disponível em: http://www.tratabrasil.org.br/saneamento/ principais-estatisticas/no-brasil/agua Acesso em: 27 set. 2020.

30 HARVEY, David. O direito à cidade. Folha de São Paulo, Piauí, n. 82, jul. 2013. Disponível em: https://piaui.folha.uol.com.br/ materia/o-direito-a-cidade/ Acesso em: 17 set. 2020.

31 SECCHI, Bernardo. La ciudad de los ricos y la ciudad de los pobres. Madrid: Catarata, 2015. p. 22.

32 SECCHI, Bernardo. La ciudad de los ricos y la ciudad de los pobres. Madrid: Catarata, 2015. p. 22.

33 MORIN, Edgar. A via para o futuro da bumanidade. Rio de Janeiro: Bertrand Brasil, 2013.

34 PETERMAN, Vânia; CRUZ, Paulo Márcio. (Des)Igualdade e sustentabilidade social: do patrimônio ambiental todos são herdeiros. Justiça do Direito, v. 31, n. 1, p. 24-44, jan./abr. 2017. p. 30.
} 
mentais, a fim de que possa ser invocado em prol da resolução dos conflitos contemporâneos, especialmente em razão da sua intensa vinculação com a dignidade humana.

\section{A fundamentalidade do direito à cidade}

Os direitos inerentes ao homem são a origem teórica do reconhecimento dos direitos humanos, em razão de carregarem consigo a compreensão de que devem ser a ele garantidos a qualquer tempo, independentemente de previsão expressa.

Sob a influência do cristianismo, a terminologia "direitos do homem" se baseava no direito natural, sendo possível concluir que o conteúdo dos direitos humanos encontra raízes no jusnaturalismo. A sua simples existência já tornava o homem titular de direitos naturais e inalienáveis.

Contudo, essas raízes não são a exclusiva matriz genética da árvore genealógica dos direitos humanos. Afinal, o contratualismo que concebeu a organização dos Estados-membros e gerou o sistema de positivação e proteção de tais direitos foi igualmente essencial para o reconhecimento dos direitos humanos.

Ao se fazer menção ao termo, busca-se configurar que existem direitos garantidos,

[...] por normas de índole internacional, isto é, por declarações ou tratados celebrados entre Estados com o propósito específico de proteger os direitos (civis e políticos; econômicos, sociais e culturais etc.) das pessoas sujeitas à sua jurisdição ${ }^{35}$.

Nessa ordem de ideias, Piovesan afirma que:

[...] considerando a historicidade dos direitos, destaca-se a chamada concepção contemporânea de direitos humanos, que veio a ser introduzida pela Declaração Universal de 1948 e reiterada pela Declaração de Direitos Humanos de Viena de 1993.36

Os direitos humanos são direitos protegidos pela ordem internacional (especialmente por meio de tratados multilaterais, globais ou regionais) contra as violações e arbitrariedades que um Estado possa cometer às pessoas sujeitas à sua jurisdição.

São direitos indispensáveis a uma vida digna e que, por isso, estabelecem um nível protetivo (standard) mínimo que todos os Estados devem respeitar, sob pena de responsabilidade internacional.

Assim, os direitos humanos são direitos que garantem às pessoas sujeitas à jurisdição de um dado estado meios de vindicação de seus direitos, para além do plano interno, nas instâncias internacionais de proteção (v.g., em nosso entorno geográfico, perante a Comissão Interamericana de Direitos Humanos, que poderá submeter a questão à Corte Interamericana de Direitos Humanos). ${ }^{37}$

A íntima relação e, ao mesmo tempo, a distinção não ontológica entre direitos humanos e direitos fundamentais é demonstrada quando delineados os conceitos, inicialmente elaborados pela doutrina jurídica alemã e que, posteriormente, receberam importantes contribuições de diversos doutrinadores.

Consoante Comparato ${ }^{38}$, os direitos fundamentais são os direitos humanos,

[...] reconhecidos como tais pelas autoridades às quais se atribui o poder político de editar normas, tanto no interior dos Estados quanto no plano internacional; são os direitos humanos positivados nas Constituições, leis e tratados internacionais.

Com o advento da CRFB/88, erigiu-se ao cenário nacional um significativo repertório básico de direitos

35 MAZZUOLI, Valério de Oliveira. Curso de Direitos Humanos. 5. ed. Rio de Janeiro: Forense, 2018. p. 23.

36 PIOVESAN, Flávia. Direitos humanos e justiça internacional. 2. ed. São Paulo: Saraiva, 2011. p. 36.

37 MAZZUOLI, Valério de Oliveira. Curso de Direitos Humanos. 5. ed. Rio de Janeiro: Forense, 2018. p. 25.

38 COMPARATO, Fábio Konder. A afirmação histórica dos direitos humanos. 6. ed. São Paulo: Saraiva, 2010. p. 70-71. 
e garantias individuais e, consequentemente, os direitos humanos.

Mediante a sua positivação, os então direitos fundamentais ${ }^{39}$ passaram a integrar, aliados aos princípios estruturais e organizacionais, o núcleo substancial da ordem normativa constitucional. ${ }^{40}$

Descritos, de maneira ampla, no rol do artigo $5^{\circ}$ da $\mathrm{CRFB} / 88^{41}$, esses direitos receberam status jurídico

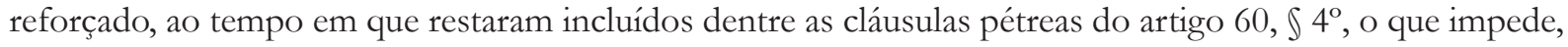
consequentemente, a sua supressão ou desgaste por obra do poder constituinte derivado.

Dentre eles figuram o direito à vida, à saúde, à educação, à moradia ao meio ambiente e à propriedade, dentre outros. Registre-se, entretanto, que os direitos fundamentais previstos não impedem que outros que derivem do regime democrático, dos tratados internacionais e dos princípios adotados pelo ordenamento sejam a ele incluídos. ${ }^{42}$

Afinal, os direitos fundamentais encontram-se em permanente estado de renascimento e ressignificação, a exemplo do direito à cidade, que também se acha em constante evolução.

Nesse patamar, a Teoria dos Direitos Fundamentais nos confere lastro suficiente a compreender o direito à cidade como um dos seus elementos, especialmente considerando-se que os espaços urbanos exigem ser pensados e projetados numa congregação de direitos, a fim de que a cidade, muitas vezes tão hostil, especulativa e segregadora, seja projetada e concretizada a partir de perspectivas plurais que possam recriar uma cidade mais humana.

Tratando-se de um direito humano e este intensamente conectado à dignidade humana, ambos deverão ser encontrados de mãos dadas no cenário urbano, unindo as franjas que compõem o tecido social.

O direito à cidade retira sua validade dos princípios constitucionais da dignidade da pessoa humana e da solidariedade, assim como dos objetivos fundamentais da República Federativa do Brasil ${ }^{43}$.

Referidos princípios, cumpre frisar, são eixos axiológicos de interpretação constitucional e, também, vértices centrais que espargem e validam os direitos fundamentais.

Possível afirmar, ainda, que o direito à cidade possui complexidade suficiente a ensejar o manejo de conhecimentos sociológicos, históricos, econômicos e ecológicos de diversas áreas, conformando-se como um direito com características interdisciplinares, que não somente sofre influência, mas também recebe aportes de alguns ramos autônomos do Direito, e que se encontra sob o manto da Carta Maior brasileira.

Assim, para vislumbrar a cidade com base em um direito fundamental, cumpre que se verifiquem os seus análogos propósitos, traduzindo-se em desdobramento dos mencionados princípios, dos quais, também, retira a sua validade.

Ao experimentar o ambiente urbano, o indivíduo passou a usufruir dos recursos ali disponíveis, exercendo a sua liberdade e deixando transparecer que, mesmo à época inicial de sua conformação, o direito à cidade já nutria íntima relação com o exercício dos direitos em amplo senso ${ }^{44}$.

\footnotetext{
39 Ferrajoli os conceitua como sendo todos “aquellos derechos subjetivos que corresponden universalmente a 'todos' los seres humanos en cuanto dotados del status de personas, de ciudadanos o personas con capacidad de obrar." FERRAJOLI, Luigi. Derechos y garantias: la ley del más débil. Madri: Editorial Trotta, 2004. p. 37.

40 SARLET, Ingo Wolfgang. Eficácia dos direitos fundamentais: uma teoria geral dos direitos fundamentais na perspectiva constitucional. 11. ed. Porto Alegre: Livraria do Advogado Editora, 2012, p. 62.

$41 \mathrm{O}$ mencionado artigo $5^{\circ} \mathrm{da} \mathrm{CRFB} / 88$ possui 78 incisos.

${ }^{42}$ Art. $5^{\circ}, \sqrt{ } 2^{\circ}$, da $\mathrm{CRFB} / 88$ : “Os direitos e garantias expressos nesta Constituição não excluem outros decorrentes do regime e dos princípios por ela adotados, ou dos tratados internacionais em que a República Federativa do Brasil seja parte."

43 Art. $3^{\circ}$ : Constituem objetivos fundamentais da República Federativa do Brasil: I - construir uma sociedade livre, justa e solidária; II - garantir o desenvolvimento nacional; III - erradicar a pobreza e a marginalização e reduzir as desigualdades sociais e regionais; IV - promover o bem de todos, sem preconceitos de origem, raça, sexo, cor, idade e quaisquer outras formas de discriminação.

44 Diversas expressões são empregadas para designar os direitos fundamentais, dentre elas "direitos naturais", "direitos humanos", "direitos humanos fundamentais", "direitos do homem", "direitos individuais", "direitos públicos subjetivos", "liberdades funda-
} 
Nesse cenário, a relação formada entre o homem e as cidades transpassa o campo político e alcança o jurídico, demonstrando que o espaço urbano se conecta em sua integralidade e a todo tempo com os direitos fundamentais e qualquer tentativa de separação seria infrutífera, a se considerar a automaticidade de interlocução existente entre eles.

Os vínculos existentes se espraiam não de maneira isolada, mas da primeira à última dimensão ${ }^{45}$ dos direitos fundamentais, gerando, assim, uma pluralidade dimensional.

\section{0 direito à cidade como polo aglutinador de diversas dimensões dos direitos fundamentais}

O direito à cidade opera como polo aglutinador das diversas dimensões dos direitos fundamentais, pois a sua efetiva realização depende de vínculos intensos com direitos históricos e recentes que precisam ser harmonizados e concretizados.

A amplitude dimensional já pode ser identificada a partir do próprio conceito de cidade sustentável, contemplado no artigo $2^{\circ}$ do Estatuto da Cidade (Lei n. ${ }^{\circ}$ 10.257/2001) como sendo o "direito à terra urbana, à moradia, ao saneamento ambiental, à infraestrutura urbana, ao transporte e aos serviços públicos, ao trabalho e ao lazer, para as presentes e futuras gerações".

A primeira dimensão forma a base física indispensável para a estruturação da cidade, à medida que se trata do direito fundamental de propriedade que deve, também, ser funcionalizado para contemplar vínculos com a coletividade e com os legítimos interesses não humanos e das futuras gerações.

$\mathrm{Na}$ CRFB/88 o referido direito foi positivado no artigo $5^{\circ}$, incisos XXII e XXVI ${ }^{46}$, configurando-se como norma de ordem pública e interesse social, além de conformar a função social da propriedade, expandindo-a para função social da cidade.

Os dois caminhos levam ao mesmo objetivo e se complementam. A propriedade funcionalizada e a cidade funcionalizada se traduzem em dois institutos comprometidos com valores constitucionais.

Nessa ordem de ideias, a função social da propriedade urbana foi inserida no art. $182, \S 2^{\circ}$, da CRFB/88, ao ser registrado que "a propriedade urbana cumpre sua função social quando atende às exigências fundamentais de ordenação da cidade expressas no plano diretor."

Esse direito é estendido, por lógica, às populações residentes em áreas rurais, a fim de que "não sofram os efeitos negativos da concentração de infraestrutura e de políticas públicas no perímetro urbano e da falta

mentais", "liberdades públicas" e "direitos fundamentais do homem". Entretanto, esta pesquisadora compactua com o preceituado por Sarlet, para quem existe a "necessidade de se adotar uma terminologia (e de um correspondente conceito) única e, além disso, constitucionalmente adequada". SARLET, Ingo Wolfgang; MARINONI, Luiz Guilherme; MITIDIERO, Daniel. Curso de Direito Constitucional. 7. ed. São Paulo: Saraiva, 2018. p. 248.

45 Deve ser registrado que não há consenso a respeito da expressão mais precisa para abordar os direitos fundamentais, havendo parte da doutrina que prefere a terminologia dimensão, a qual será utilizada no presente artigo, e outros autores que utilizam geração, "naipe" ou "famílias". SARLET, Ingo Wolfgang. A Eficácia dos direitos fundamentais: uma teoria geral dos direitos fundamentais na perspectiva constitucional. 12. ed. Porto Alegre: Livraria do Advogado, 2015. p. 45-46.

46 Art. $5^{\circ}$ [...] XXII - é garantido o direito de propriedade; XXIII - a propriedade atenderá a sua função social; XXIV - a lei estabelecerá o procedimento para desapropriação por necessidade ou utilidade pública, ou por interesse social, mediante justa e prévia indenização em dinheiro, ressalvados os casos previstos nesta Constituição; XXV - no caso de iminente perigo público, a autoridade competente poderá usar de propriedade particular, assegurada ao proprietário indenização ulterior, se houver dano; XXVI - a pequena propriedade rural, assim definida em lei, desde que trabalhada pela família, não será objeto de penhora para pagamento de débitos decorrentes de sua atividade produtiva, dispondo a lei sobre os meios de financiar o seu desenvolvimento [...].

47 Segundo o artigo 182, $\int 1^{\circ}$, da CRFB/88, "Plano diretor é uma lei municipal, aprovada pela Câmara Municipal de Vereadores, obrigatória nas cidades com mais de 20 mil habitantes, sendo "o instrumento básico da política de desenvolvimento e de expansão urbana". 
de suporte às dinâmicas econômicas urbano-rurais." ${ }^{48}$

A profunda modificação no conceito original de propriedade, com a positivação de uma função social, conectou-a, estreitamente, aos direitos fundamentais de segunda dimensão decorrentes do desenvolvimento industrial e doutrinas socializantes, uma vez que tais direitos passaram a cuidar da promoção de igualdade entre os cidadãos, afastada a noção primária, egoística e individualista configurada no direito absoluto de fruir, gozar e abusar.

A dimensão social restou, assim, evidenciada e possui no direito à moradia a sua maior expressão, pois materializa o berço que acolhe, o lar que abriga, a estrutura física que protege e assegura dignidade para pessoas e famílias.

A segunda dimensão é necessariamente reforçada pelo amplo conjunto de ações positivas por parte do Estado, traduzido em políticas públicas urbanas, asseguradoras do direito à cidade, a exemplo do saneamento, da infraestrutura, do transporte, do lazer, do trabalho e da saúde.

Não há de se falar em políticas governamentais efetivas e eficazes que estejam relacionadas ao direito à cidade quando estas não contemplam direitos de primeira grandeza como a moradia.

Com base nessa perspectiva, Comparato adverte: "sendo objetivo da justiça proporcional ou distributiva instaurar a igualdade substancial de condições de vida, é óbvio que ela só pode realizar-se por meio de políticas públicas ou programas de ação governamental." 49

Nesse sentir, as políticas públicas prestacionais adquirem relevo significativo, posto que devem conferir valorização ao indivíduo, assim como contribuir para a melhoria da sua qualidade de vida, bem como de sua relação com o espaço urbano e todo o mosaico social.

Daí porque a CRFB/88 estabelece, em seu artigo 182, que o plano diretor é o instrumento básico da política de desenvolvimento e de expansão urbana, que deve ser executada pelo poder público municipal, conforme diretrizes gerais fixadas em lei, com o objetivo de ordenar o pleno desenvolvimento das funções sociais da cidade e garantir o bem-estar de seus habitantes.

É por meio das políticas públicas municipais que o direito à cidade pode ser efetivamente exercido. Afinal, a União e os Estados constituem uma representação administrativa dos Governos Federal e Estaduais, mas sem conexão direta com as vidas dos habitantes das cidades, todas calcadas em políticas públicas locais, oferecidas por seus respectivos municípios.

Para muito além das dimensões clássicas, na atual quadra da história devem, também, ser realçadas as conexões desse direito com a coletividade, inclusive com os não humanos e com o futuro.

Um dos pilares fundamentais de toda e qualquer cidade é a sustentabilidade, o que se confirma em razão da previsão normativa constituciona ${ }^{50}$ e ordinária, que estabeleceu políticas públicas em todas as esferas nacional, estaduais e municipais - a exemplo da gestão e tratamento de resíduos sólidos e saneamento básico, conforme estabelecido nas Leis Federais n. 11.445/07 (alterada pela n. 14.026, de 15 de julho de 2020) e 12.305/10 que reconheceu expressamente o princípio do desenvolvimento sustentável.

Nesse contexto, verifica-se a conexão do direito à cidade à terceira dimensão dos direitos fundamentais (direitos de fraternidade), que são aqueles de titularidade transindividual (difusa ou coletiva) e concebidos para a proteção de toda a coletividade.

Recebem a alcunha de direitos de fraternidade em razão de se destinarem às presentes e, também, às futuras gerações, garantindo-lhes minimamente o que existe para as atuais. Esses direitos tutelam o desen-

48 OSÓRIO, Letícia Marques. O direito à cidade como direito humano coletivo. In: FERNANDES, Edésio; ALFONSIN, Betânia (coords.) Direito urbanístico: estudos brasileiros e internacionais. Belo Horizonte: Del Rey, 2006.

49 COMPARATO, Fábio Konder. A afirmação histórica dos direitos humanos. 12. ed. São Paulo: Saraiva, 2019. p. 541.

50 Artigo 225, caput e parágrafos. 
volvimento, a comunicação, o patrimônio comum da humanidade e o meio ambiente.

Dentre eles, o direito à cidade se enquadra como uma modalidade e uma classificação do meio ambiente, possuindo com ele intrínseca correlação em razão da garantia de sadia qualidade de vida dos cidadãos, e, indubitavelmente, gerando vínculos com bens difusos e coletivos em amplo senso, sendo exatamente essa robusta amarra que o emancipa do direito administrativo.

Por ser assim, as questões urbana e ambiental, comumente debatidas isolada e separadamente, passaram a ser tratadas de forma integrada, a fim de se alcançar proposta de espaços de assentamento humano sustentáveis.

Desse modo, no item 7 da Conferência de Berlim, a proposição foi de que: “as cidades devem ser organizadas de forma a desempenhar um papel decisivo na redução e eliminação de padrões insustentáveis de transportes e de construções ambientalmente sadios." ${ }^{51}$

Sob essa concepção internacional, é possível contemplar um direito à cidade que traz, em sua amplitude conceitual, a íntima conexão entre os direitos humanos fundamentais contemporâneos, essencialmente a garantia a espaços territoriais sustentavelmente organizados, de forma a oferecer sadia qualidade de vida a seus cidadãos, com plena participação social democrática nas políticas públicas estatais.

A fim de acompanhar a evolução mundial e suas revoluções informacionais e tecnológicas, foram delineados os direitos descritos como de quarta dimensão ou direitos de solidariedade lato sensu.

Estes são considerados “jovens" no contexto jurídico atual e precisam ser compreendidos em meio à globalização e às velozes modificações experimentadas pelo Estado de Direito contemporâneo.

A solidariedade expressa, conforme preconizado por Sarlet e Fensterseifer ${ }^{52}$, "a necessidade (e, na forma jurídica, o dever) fundamental de coexistência (e cooperação) do ser humano em um corpo social, formatando a teia de relações intersubjetivas e sociais que se traçam no espaço da comunidade estatal."

Impulsionados pela conjuntura atual, encontram-se compreendidos nesse cenário os direitos fundamentais à democracia, à informação, ao pluralismo e ao patrimônio genético, os quais devem atingir a máxima universalidade, permeando, assim, todas as relações tecidas no seio da sociedade.

Globalizar direitos fundamentais, segundo Bonavides ${ }^{53}$, seria o mesmo que universalizá-los no meio institucional, posto que somente assim um conceito aufere humanização e legitimidade que, de outro modo, conforme vem ocorrendo, poderá servir, unicamente, ao futuro.

A participação democrática social ou democracia participativa na formação da vontade do Estado decorre da Declaração Universal dos Direitos Humanos de 1948. Essa participação foi inicialmente tratada no artigo 21 do mencionado documento: "todo homem tem o direito de tomar parte no governo de seu país, diretamente ou por intermédio de representantes livremente escolhidos." 54

Esse formato encontra-se, assim, intrinsecamente vinculado ao Princípio da Solidariedade, porquanto, como ensinam Terra e Pellegrini ${ }^{55}$,

[...] a solidariedade, princípio firmado pela dogmática jurídica no século XX, apresenta-se, na atualidade, com uma missão difícil, que passa por solidificar a democracia, humanizar as relações, conduzir o indivíduo à reflexão e concretizar a dignidade da pessoa humana.

\footnotetext{
51 MARQUES, José Roberto. Meio Ambiente urbano. Rio de Janeiro: Forense Universitária, 2005. p. 91-92.

52 SARLET, Ingo Wolfgang; FENSTERSEIFER, Tiago. Direito Constitucional Ambiental: constituição, direitos fundamentais e proteção do ambiente. 5. ed. São Paulo: Revista dos Tribunais, 2017. p. 65.

53 BONAVIDES, Paulo. Curso de direito constitucional. 19. ed. São Paulo: Malheiros, 2009. p. 571.

54 ORGANIZAÇÃO DAS NAÇÕES UNIDAS. Declaração Universal dos Direitos Humanos. Disponível em: https://www.unicef.org/ brazil/declaracao-universal-dos-direitos-humanos\#: :text=Artigo $\% 2021$-,1.,servi $\% \mathrm{C} 3 \% \mathrm{~A} 7 \mathrm{o} \% 20 \mathrm{p} \% \mathrm{C} 3 \% \mathrm{BAblico} \% 20 \mathrm{do} \% 20$ seu $\% 20 \mathrm{pa} \% \mathrm{C} 3 \%$ ADs Acesso em: 28 set. 2020.

55 TERRA, R. B. M. da R. B.; PELLEGRINI, G. K. de F. Inter-relações entre o direito público e o privado: uma abordagem do princípio da solidariedade nas relações privadas. In: REIS, J. R.; Cerqueira, K. L (orgs.). Santa Cruz do Sul: IPR, 2013. p. 89.
} 
Ao ser respeitado o Princípio de Participação Popular no planejamento das cidades, torna-se o projeto destas não um projeto de governo, mas de todo o povo, reforçando o espírito de cidadania e de gestão democrática e eficiente do espaço urbano.

A importância da observância de tal princípio reside no fato de que as normas urbanísticas definidas ou alteradas pelos Municípios exigem ser objeto de participação popular, a fim de legitimar a atuação do poder público.

Para que isso ocorra devidamente na pós-modernidade, torna-se necessário que os cidadãos tenham acesso à inclusão digital e a todos os tipos de Tecnologias de Informação e Comunicações (TICs) que circundam as clássicas opções, permitindo que se informem sobre os problemas das cidades e apontem as soluções desejadas.

Nesse sentido, a e-democracia, instituto contemporâneo de participação democrática, indica uma forma nova de buscar a implementação da participação popular por meio da internet e demais mídias digitais.

No que toca ao entrelaçamento do direito à cidade com a quinta dimensão dos direitos fundamentais, faz-se necessário, de antemão, apontar que não há consenso doutrinário em relação a sua formação, tampouco, no que concerne aos direitos por ela abarcados.

Para alguns autores, como Bonavides ${ }^{56}$, a apontada dimensão contempla, apenas, o direito à paz. Para outros, como Oliveira Junior ${ }^{57}$ e Wolkmer ${ }^{58}$, ela comporta o direito à sociedade tecnológica e de informação, o ciberespaço, a internet e a realidade virtual.

O mencionado direito, para Bonavides, "é concebido ao pé da letra qual direito imanente à vida, sendo condição indispensável ao progresso de todas as nações, grandes e pequenas, em todas as esferas." 59

Um dos documentos internacionais que talvez tenha apresentado a melhor definição sobre o tema pode ser considerado a "Carta da Terra", em que a paz está estabelecida no princípio $16, f$, como "a plenitude criada por relações corretas consigo mesmo, com outras pessoas, outras culturas, outras vidas, com a Terra e com a totalidade maior da qual somos parte." ${ }^{60}$

Entretanto, atrelados aos indutores de uma coletividade pacífica e democrática, exsurge uma nova realidade, que contempla o direito à sociedade tecnológica e de informação, ao ciberespaço, à internet e à realidade virtual.

Essa nova existência tecnológica permitiu, à guisa de ilustração, que fossem fomentados grandes protestos pelas ruas de diversas cidades do mundo, demonstrando insatisfações e reivindicando uma gama diversificada de direitos pelas populações.

A mencionada realidade dialoga, também, com a governança das cidades, agora tida como governança digital, uma vez que inúmeras administrações públicas têm disponibilizado portais, paralelamente aos meios tradicionais, nos quais os cidadãos podem intervir em processos administrativos, visando informar, informar-se ou ser informado de assuntos que poderão impactar no cotidiano urbano.

$\mathrm{O}$ direito à cidade, em meio ao processo de transformação social, assume maior destaque, em razão do choque existente em seus aspectos político, social e jurídico, até mesmo em razão do contraste de uma lógica privatizante e o direito metaindividual à fruição do bem comum cidade com todos os seus direitos inerentes.

\footnotetext{
56 BONAVIDES, Paulo. A quinta geração de direitos fundamentais. Direitos Fundamentais \& Justiça, ano 2, n. 3, abr./jun. 2008 . p. 82. 57 OLIVEIRA JR., José Alcebíades de. Teoria jurídica e novos direitos. Rio de Janeiro: Lúmen Juris, 2000. p. 100.

58 WOLKMER, Antonio Carlos. Introdução aos fundamentos de uma teoria geral dos "novos" direitos. Revista Jurídica Unicuritiba, v. 2, n. 31, 2013. Disponível em: http://revista.unicuritiba.edu.br/index.php/RevJur/article/view/593 Acesso em: 26 set. 2020.

59 BONAVIDES, Paulo. A quinta geração de direitos fundamentais. Direitos Fundamentais \& Justica, ano 2, n. 3, abr./jun. 2008 . p. 82.

60 BRASIL. Ministério do Meio Ambiente. Carta da Terra. 2000. Disponível em: https://www.mma.gov.br/estruturas/agenda21/_arquivos/carta_terra.pdf Acesso em: 27 set. 2020.
} 


\section{Considerações finais}

A estruturação histórica da cidade, evidencia uma trajetória marcada por intensos desafios, conflitos e dificuldades extremas de acesso aos direitos fundamentais. Sua adequada compreensão, na perspectiva da sustentabilidade, requer uma análise ampla e que envolva os aspectos sociais, econômicos e ambientais.

Nas últimas décadas, constata-se maior sensibilização dos estudiosos do Direito para compreender a cidade como direito. O quadro normativo, internacional e nacional também sofreu profícua evolução, merecendo especial destaque o Estatuto da Cidade.

A intensa vinculação do direito à cidade à dignidade humana, e a outros direitos essenciais para a sua concretização, assegura a esse direito dimensão material de um autêntico direito fundamental.

Todavia, a máxima efetividade desse direito fundamental somente será alcançada com a compreensão da sua perspectiva multidimensional, ou seja, da sua intensa e concreta vinculação com todas as dimensões dos direitos fundamentais. Somente assim, o direito à cidade poderá ser operacionalmente implementado com forte vocação para ser instrumento de dignidade humana apto a ser aplicado em harmonia com outros direitos fundamentais diretamente relacionados.

A multiplicidade de dimensões do direito à cidade também é justificada no papel exercido pelos mais diversos atores e instituições na sua colaborativa efetivação. Afinal, a construção do direito fundamental à cidade deve ser necessariamente um afazer compartilhado que atrai intensa participação e comunicação entre os mais diversos atores, Estado e sociedade civil. Por todo exposto, fica demonstrada a intensa contribuição que o Direito Constitucional pode prestar para a efetivação do direito fundamental à cidade.

\section{Referências}

ALVES, Henrique Prates da Fonseca. Vulnerabilidade socioambiental na metrópole paulistana: uma análise sociodemográfica das situações de sobreposição espacial de problemas e riscos sociais e ambientais. Revista Brasileira de Estudos de População, v. 23, p. 43-59, 2006.

BONAVIDES, Paulo. A quinta geração de direitos fundamentais. Direitos Fundamentais \& Justiça, ano 2, n. 3 , abr./jun. 2008.

BONAVIDES, Paulo. Curso de direito constitucional. 19. ed. São Paulo: Malheiros, 2009.

BRASIL. Ministério do Meio Ambiente. Carta da Terra. 2000. Disponível em: https://www.mma.gov.br/ estruturas/agenda21/_arquivos/carta_terra.pdf Acesso em: 27 set. 2020.

CASTELLS, Manuel. Sociedade em rede. 20. ed. São Paulo: Paz e Terra, 2019.

COMPARATO, Fábio Konder. A afirmação histórica dos direitos humanos. 6. ed. São Paulo: Saraiva, 2010.

COMPARATO, Fábio Konder. A afirmação histórica dos direitos humanos. 12. ed. São Paulo: Saraiva, 2019.

EUROMONITOR INTERNACIONAL. Megacities: Developing Country Domination. 2018. Disponível em: https://go.euromonitor.com/strategy-briefing-cities-2018- megacities.html Acesso em: 26 set. 2020.

FERRAJOLI, Luigi. Derechos y garantias: la ley del más débil. Madri: Editorial Trotta, 2004.

FERRER, Gabriel Real. El principio de no regresión ambiental a la luz del paradigma de la sostenibilidad. In: CHACON, Mario Peña (org.). Elprincipio de no regresión ambiental en iberoamérica. Gland (Suiza): Universidad de Costa Rica: Unión Internacional para la Conservación de la Naturaleza (UICN). Comisión Mundial de Derecho Ambiental, 2015. Disponível em: https://portals.iucn.org/library/sites/library/files/documents/ 
EPLP-084.pdf Acesso em: 26 set. 2020.

FREITAS, Juarez. Sustentabilidade: direito ao futuro. 2. ed. Belo Horizonte: Fórum, 2012.

GARCIA, Denise Schmitt Siqueira. Sustentabilidade e Ética: um debate urgente e necessário. Revista Direito Culturais - URI, Santo Ângelo, v. 15, p. 51-75, 2019.

GIDDENS, A. As consequências da modernidade. São Paulo: Ed. Unesp, 1990.

HARVEY, David. O direito à cidade. Folha de São Paulo, Piauí, n. 82, jul. 2013. Disponível em: https://piaui. folha.uol.com.br/materia/o-direito-a-cidade/ Acesso em: 17 set. 2020.

INSTITUTO BRASILEIRO DE GEOGRAFIA E ESTATÍSTICA. População do Brasil. Disponível em: https://www.ibge.gov.br/apps/populacao/projecao/ Acesso em: 26 set. 2020.

INSTITUTO BRASILEIRO DE GEOGRAFIA E ESTATÍSTICA. Sintese de Indicadores Sociais (SIS). 2018. Disponível em: https://www.ibge.gov.br/estatisticas/sociais/habitacao/9221-sintese-de-indicadores-sociais.html? $=\& \mathrm{t}=$ O-que-e Acesso em: 28 set. 2020.

INSTITUTO TRATA BRASIL. Painel Saneamento Brasil. 2018. Disponível em: http://www.tratabrasil.org. br/saneamento/principais-estatisticas/no-brasil/agua Acesso em: 27 set. 2020.

MARICATO, Ermínia. Brasil, cidades: alternativas para a crise urbana. Petrópolis, RJ: Vozes, 2001.

MARQUES, José Roberto. Meio Ambiente urbano. Rio de Janeiro: Forense Universitária, 2005.

MAZZUOLI, Valério de Oliveira. Curso de Direitos Humanos. 5. ed. Rio de Janeiro: Forense, 2018.

MORIN, Edgar. A via para o futuro da bumanidade. Rio de Janeiro: Bertrand Brasil, 2015.

MORIN, Edgar. A via para o futuro da bumanidade. Rio de Janeiro: Bertrand Brasil, 2013.

NALINI, José Renato; SILVA NETO, Wilson Levy Braga da. Cidades inteligentes e sustentáveis: desafios conceituais e regulatórios. Revista de Direito da Administração Pública, v. 1, n. 1, 2017. Disponível em: http:// www.redap.com.br/index.php/redap/article/view/107 Acesso em: 28 set. 2020.

OLIVEIRA JR., José Alcebíades de. Teoria jurídica e novos direitos. Rio de Janeiro: Lúmen Juris, 2000.

ORGANIZAÇÃO DAS NAÇÕES UNIDAS HABITAT. Programa das Nações Unidas para os Assentamentos Humanos. World Cities Report 2016. Disponível em: http://wcr.unhabitat.org/ Acesso em: 28 set. 2020.

ORGANIZAÇÃO DAS NAÇÕES UNIDAS HABITAT. Relatório Cidades do Mundo. 2016. Disponível em: https://nacoesunidas.org/atual-modelo-de-urbanizacao-e-insustentavel-onu-habitat-relatorio/ Acesso em: 28 set. 2020 .

ORGANIZAÇÃO DAS NAÇÕES UNIDAS. Declaração Universal dos Direitos Humanos. Disponível em: $\quad$ https://www.unicef.org/brazil/declaracao-universal-dos-direitos-humanos\#: :text=Artigo \%20 21-,1.,servi\%C3\%A7o\%20p\%C3\%BAblico\%20do\%20seu\%20pa\%C3\%ADs Acesso em: 28 set. 2020.

ORGANIZAÇÃO DAS NAÇÕES UNIDAS. ONU prevê que cidades abriguem $70 \%$ da população mundial até 2050. 2019. Disponível em: https://news.un.org/pt/story/2019/02/1660701 Acesso em: 27 set. 2020.

OSÓRIO, Letícia Marques. O direito à cidade como direito humano coletivo. In: FERNANDES, Edésio; ALFONSIN, Betânia (coords.) Direito urbanístico: estudos brasileiros e internacionais. Belo Horizonte: Del Rey, 2006.

PASOLD, Cesar Luiz. Metodologia da pesquisa jurídica: teoria e prática. 13. ed. Florianópolis: Conceito Editorial, 2015.

PATRIMÔNIO dos super-ricos brasileiros cresce US\$34 bilhões durante a pandemia, diz Oxfam. G1 Globo, 
2020. Disponível em: https://g1.globo.com/economia/noticia/2020/07/27/patrimonio-dos-super-ricos-brasileiros-cresce-us-34-bilhoes-durante-a-pandemia-diz-oxfam.ghtml Acesso em: 27 set. 2020.

PETERMAN, Vânia; CRUZ, Paulo Márcio. (Des)Igualdade e sustentabilidade social: do patrimônio ambiental todos são herdeiros. Justiça do Direito, v. 31, n. 1, p. 24-44, jan./abr. 2017.

PIOVESAN, Flávia. Direitos bumanos e justiça internacional. 2. ed. São Paulo: Saraiva, 2011.

RIFKIN, Jeremy. A terceira revolução industrial: como o poder lateral está transformando a energia, a economia e o mundo. São Paulo: M. Books do Brasil, 2012.

RIFKIN, Jeremy. La era del acesso. Buenos Aires: Paidós, 2000.

SARLET, Ingo Wolfgang. A Eficácia dos direitos fundamentais: uma teoria geral dos direitos fundamentais na perspectiva constitucional. 12. ed. Porto Alegre: Livraria do Advogado, 2015.

SARLET, Ingo Wolfgang. Eficácia dos direitos fundamentais: uma teoria geral dos direitos fundamentais na perspectiva constitucional. 11. ed. Porto Alegre: Livraria do Advogado, 2012.

SARLET, Ingo Wolfgang; FENSTERSEIFER, Tiago. Direito Constitucional Ambiental: constituição, direitos fundamentais e proteção do ambiente. 5. ed. São Paulo: Revista dos Tribunais, 2017.

SARLET, Ingo Wolfgang; MARINONI, Luiz Guilherme; MITIDIERO, Daniel. Curso de Direito Constitucional. 7. ed. São Paulo: Saraiva, 2018.

SCHWAB, Klaus. A quarta revolução industrial. São Paulo: Edipro, 2016.

SECCHI, Bernardo. La cindad de los ricos y la ciudad de los pobres. Madrid: Catarata, 2015.

TERRA, R. B. M. da R. B.; PELLEGRINI, G. K. de F. Inter-relações entre o direito público e o privado: uma abordagem do princípio da solidariedade nas relações privadas. In: REIS, J. R.; Cerqueira, K. L (orgs.). Santa Cruz do Sul: IPR, 2013.

UNESCO. Educação para a cidadania global (ECG): a abordagem da UNESCO. 2015. Disponível em: http:// www.unesco.org/new/fileadmin/MULTIMEDIA/FIELD/Brasilia/pdf/brz_ed_global_citizenchip_brochure_pt_2015.pdf Acesso em: 26 set. 2020.

UNITED NATIONS POPULATION FUND. The power of choice. Disponível em: https:/ /www.unfpa.org/ swop-2018 Acesso em: 26 set. 2020.

WOLKMER, Antonio Carlos. Introdução aos fundamentos de uma teoria geral dos "novos" direitos. Revista Jurídica Unicuritiba, v. 2, n. 31, 2013. Disponível em: http://revista.unicuritiba.edu.br/index.php/RevJur/ article/view/593 Acesso em: 26 set. 2020.

WORLDOMETERS. População mundial. Disponível em: https://www.worldometers.info/br/ Acesso em: 26 set. 2020. 
Para publicar na revista Brasileira de Políticas Públicas, acesse o endereço eletrônico www.rbpp.uniceub.br

Observe as normas de publicação, para facilitar e agilizar o trabalho de edição. 